\title{
Diversity of the bacteria in the roots of sugarcane used to produce Wasanbon in Kagawa, Japan
}

\author{
Supriadi, Natsuki Shimoura, Masahiro Miyaji, Shigeyuki Tajima, Mika Nomura* \\ Faculty of Agriculture, Kagawa University, Miki-cho, Kita-gun, Kagawa 761-0795, Japan \\ *E-mail:nomura@ag.kagawa-u.ac.jp Tel: +81-87-891-3135 Fax: +81-87-891-3021
}

Received November 18, 2019; accepted January 7, 2020 (Edited by H. Kouchi)

\begin{abstract}
Soil bacteria are an important factor in the cycle of nutrients in soil, while root bacteria in the internal tissues of plants can promote plant growth. The aim of this research was to study the diversity of root bacteria of sugarcane grown in Kagawa, Japan. The sugarcane, derived from Saccharum sinense and grown only in this area, is used as a raw material for Wasanbon (a fine-grained Japanese sugar) and is characterized by thin stalks and a low sugar content. To determine its bacterial diversity, bacterial DNA was extracted from the soil and roots, and 16S rRNA genes were sequenced. A total of 1259 operational taxonomic units (OTUs) were detected in the root bacteria and 3894 OTUs in the soil bacteria. The $\alpha$-diversity between the soil and root bacteria was significantly different. The most abundant class of root and soil bacteria was proteobacteria at more than 50 and $30 \%$, respectively. The endophyte bacteria of rhizobium were also isolated and the nifH gene was detected. The relationship between the application of nitrogen-fixing bacteria and the production of Wasanbon should be studied.
\end{abstract}

Key words: $16 \mathrm{~S}$ rRNA, endophyte, sugarcane, Wasanbon.

Sugarcane (Saccharum sp.) is the main crop in tropical areas for biofuel production and food, and the cane is characterized by thick stalks and a high sugar content. In Brazil, nitrogen is supplied to sugarcane by endophytic bacteria that can fix nitrogen at more than $40 \mathrm{~kg} \mathrm{Nha}^{-1}$ year $^{-1}$ (Urquiaga et al. 2012). The potential nitrogenfixing bacteria from sugarcane, especially for endophytic diazotrophs, has been widely studied (Boddey et al. 2003). Acetobacter diazotrophicus has been isolated from the roots and stems of Brazilian sugarcane (Cavalcante and Dobereiner 1988). Other nitrogen-fixing bacteria, including Herbaspirillum sp. (Olivares et al. 1996), Enterobacter sp. (Sajjad Mirza et al. 2001), Azospirillum sp. (Tejera et al. 2005), Klebsiella sp. (Govindarajan et al. 2007), Burkholderia sp. (Paungfoo-Lonhienne et al. 2013), and Bradyrhizobium sp. (de Matos et al. 2017), have been reported to be isolated from sugarcane roots, stems, and leaves, and most of the bacteria also promote plant growth.

In Japan, sugarcane is grown in a tropic or subtropic areas such as Okinawa and is characterized by thick stalks and a high sugar content (Matsuoka 2006). Kagawa is not temperate area; however, Wasanbon is produced from sugarcane grown only in this area. The varieties cultivated here, originating from $S$. sinense, are different from those in temperate regions and are characterized by a low sugar content in thin stems. There has been a report on the diversity of endophytes in the roots of four Saccharum species, S. spontaneum, S. robstum, S. barberi, and S. officinarum (Dong et al. 2018); however, there have been no reports about $S$. sinense.

The aim of this study was to determine the bacterial diversity of the roots and soil using 16S rRNA gene sequencing. The sugarcane was sampled in two different fields: one field was where wheat was cultivated the previous year and the other field was where sugarcane has been grown continuously for 10 years. Samples of sugeracane roots and soil were collected from three separate areas in each field. The sugarcane soil and roots from the field where wheat was cultivated last year were named soil-1 and root-1, respectively, while the soil and sugarcane roots from the field cultivated continuously with sugarcane for 10 years were named soil-10 and root-10, respectively. The roots and soil were collected in August 2018 when the sugarcane was in the elongation stage. The roots were washed three times with sterilized water, washed again with $70 \%$ ethanol, and then with $3 \%$ sodium hypochlorite. After sterilization, the roots were washed again three times with sterilized water.

Total bacterial genomic DNA was extracted using a PowerSoil DNA isolation kit (Qiagen, Hilden, Germany). A metagenomic amplicon sequencing library

Abbreviations: ARA, acetylene reduction activity. 
was prepared by using Illumina $16 \mathrm{~S}$ metagenomics sequencing library preparation (Preparation 16S Ribosomal RNA Gene Amplicons for the Illumina Miseq System, Illumina). In brief, the gene-specific sequences used in this study targeted the V3 and V4 region (Klindworth et al. 2013). The Illumina adapter overhang nucleotide sequences were then added to the gene-specific sequences. The Illumina overhang adapter sequences added to locus-specific sequences were forward overhang: 5'-TCG TCG GCA GCG TCA GAT GTG TAT AAG AGA CAG-[i7] and reverse overhang: $5^{\prime}$-GTC TCG TGG GCT CGG AGA TGT GTA TAA GAG ACA G-[i5]. Each i7 and i5 is listed in Supplementary Table S1. PCR was performed using a KAPA HiFi Hotstart PCR kit (Sigma-Aldrich, Boston, USA). The amplicons were removed free primers by AMPure XP beads (Beckman Coulter, USA). The quality and concentration of these amplicons were calculated using an Agilent 2100 Bioanalyzer (Agilent, CA, USA). Sequencing was performed using an Illumina Miseq platform using paired 300 reads (Illumina, San Diego, USA). All data has been registered and the accession numbers are DRA009113 to DRA009123. The plastid and mitochondria data detected in the roots were removed based on the QIIME program (Caporaso et al. 2010). The average reads obtained for Miseq showed that the identified bacterial OTUs of soil-1 and soil-10 were $3,894 \pm 102$ and 3,064 \pm 278 , respectively, and 1,114 \pm 256 and 1,259 \pm 581 for root- 1 and root- 10 , respectively. The coverage of all samples was 92 to $97 \%$. Four indices, Chaol richness index, ACE index, Shannon index, and Simpson index, were also determined to measure the $\alpha$-diversity of the microbiome (Table 1). Based on the estimation by the Chaol index, ACE index and Shannon index, the microbial diversity and microbial richness of both soil-1 and soil-10 were significantly higher than that of root- 1 and root- 10 .

The relative abundance of the microbial communities was analyzed (Figure 1). At the phylum level, eight phyla were identified at a rate of over $3 \%$ (Figure 1). The

Table 1. Richness and diversity indices for root and soil bacteria of sugarcane.

\begin{tabular}{|c|c|c|c|c|c|c|c|c|}
\hline \multirow{2}{*}{ Sample name } & \multirow{2}{*}{ Cleaned reads } & \multicolumn{7}{|c|}{ Alpha diversity index } \\
\hline & & OTUs number & Total reads & Coverage (\%) & Chaol index & ACE index & Shannon index & Simpson index \\
\hline Soil-1 & $27109 \pm 413^{\mathrm{a}}$ & $3894 \pm 102^{\mathrm{a}}$ & $25930 \pm 363^{\mathrm{a}}$ & $92 \pm 0.2^{\mathrm{a}}$ & $6723 \pm 105^{\mathrm{a}}$ & $6789 \pm 125^{\mathrm{a}}$ & $9.8 \pm 0.2^{\mathrm{a}}$ & $0.993 \pm 0.001^{\mathrm{a}}$ \\
\hline Soil-10 & $27882 \pm 128^{a}$ & $3064 \pm 278^{\mathrm{a}}$ & $27135 \pm 228^{\mathrm{b}}$ & $94 \pm 0.5^{\mathrm{a}}$ & $5603 \pm 296^{\mathrm{b}}$ & $5736 \pm 402^{\mathrm{b}}$ & $9.2 \pm 0.4^{\mathrm{b}}$ & $0.993 \pm 0.003^{\mathrm{a}}$ \\
\hline Root-1 & $27218 \pm 106^{\mathrm{a}}$ & $1114 \pm 256^{\mathrm{b}}$ & $26875 \pm 1083^{a}$ & $97 \pm 0.4^{b}$ & $2135 \pm 423^{c}$ & $2204 \pm 389^{c}$ & $4.2 \pm 0.7^{\mathrm{c}}$ & $0.795 \pm 0.045^{\mathrm{b}}$ \\
\hline Root-10 & $26383 \pm 978^{a}$ & $1259 \pm 581^{b}$ & $26188 \pm 876^{\mathrm{b}, \mathrm{a}}$ & $97 \pm 0.8^{b}$ & $2233 \pm 856^{c}$ & $2254 \pm 852^{c}$ & $5.3 \pm 2.8^{\mathrm{c}}$ & $0.841 \pm 0.1939^{\mathrm{a}}$ \\
\hline
\end{tabular}

OTU, operational taxonomical unit; ACE, abundance-based coverage estimator. Values are means \pm standard error $(n=3)$. Different letters indicate statistically significant differences at the 0.05 probability level according to Fisher's least significant difference (LSD) test.

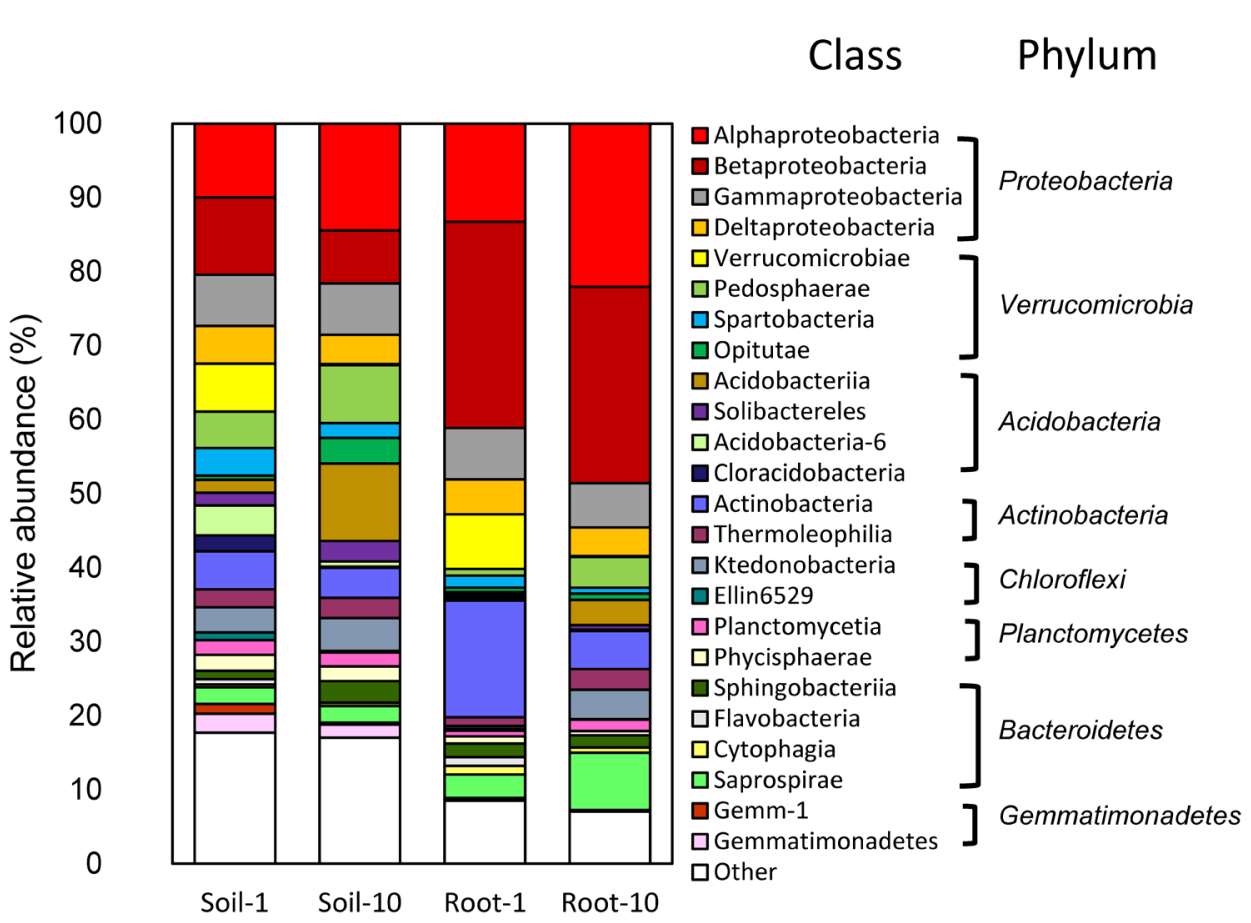

Figure 1. The relative abundance (\%) of phylum and class of bacterial community in the soil and roots of sugarcane. The taxa represented accounted for $>1 \%$ abundance in at least one sample. 'Other' is taxa with a maximum abundance of $<1 \%$ in each sample. 


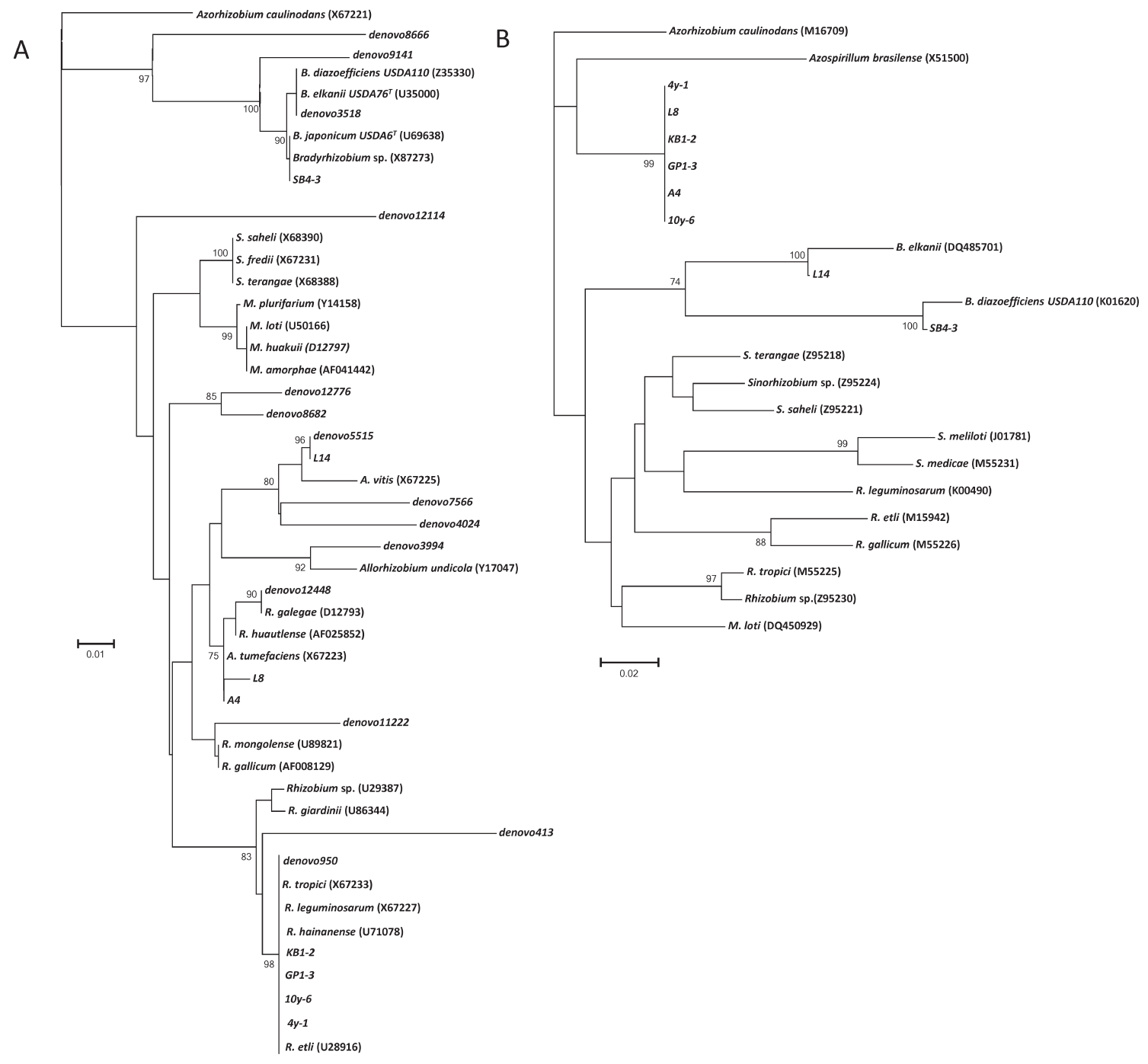

Figure 2. Phylogenetic tree of isolated bacteria from sugarcane based on 16SrRNA (A) and nifH (B) sequences. The percentage of replicate trees in which the associated taxa clustered together in the bootstrap test (100 replicates) are shown next to the branches. The evolutionary distances were computed using the Kimura 2-parameter. Evolutionary analyses were conducted in MEGA7. The accession number is indicated in parentheses. The denovo number indicates the number of Miseq data isolated in this study. SB4-3, L14, L8, A4, KB1-2, GP1-3, 10y-6, and 4y-1 were subjected to nifH sequencing after the bacteria were isolated from the medium. A., Agrobacterium; B., Bradyrhizobium; M., Mesorhizobium; R., Rhizobium; S., Sinorhizobium.

most abundant phyla in the roots and isolated bacteria from the soil were Proteobacteria, Verrucomicrobia, Acidobacteria, and Actinobacteria, which represented more than $70 \%$ of the bacterial taxa in both the soil and roots (Figure 1). The microbial communities in soil-1 and soil-10 and in root-1 and root-10 were similar. The only difference seen was Acidobacteria and Verrucomicrobia (Figure 1). These data indicate that the sugarcane continuous cropping did not change the core microbial community. These core populations are proteobacteria, which is consistent with previous results (Bissett et al. 2016; Lauber et al. 2009). Five classes were more prevalent in the root bacterial populations than in the soil bacterial populations: $\alpha$-proteobacteria, $\beta$-proteobacteria, Cytophagia, Saprospirae, and Actinobacteria (Figure 1). We speculated that these classes have a higher potential to be isolated as endophyte nitrogen-fixing bacteria. The Sphingomonas, Asticcacaulis, Agrobacterium, and Rhizobium species of the $\alpha$-proteobacteria have been identified as important nitrogen-fixing bacteria (Yeoh et al. 2017). Notably, not only $\alpha$-proteobacteria but also $\beta$-proteobacteria increased as root bacteria. $\beta$-proteobacteria were dominant in the roots at $26 \%$, an increase of approximately 2-3 times compared with the $10 \%$ in the soil. This result is consistent with a previous result in which $\beta$-proteobacteria were present at $5.7 \%$ in the roots and predominant compared with $1.4 \%$ in the soil (Yeoh et al. 2017). The $\beta$-proteobacteria identified in the sugarcane fields in Kagawa (Achromobacter, Burkholderia, Ralstonia, and Janthinobacterium) may be endogenous nitrogen-fixing bacteria. However, Acetobacter, which 
Table 2. Bacterial strains used in this study.

\begin{tabular}{llllll}
\hline \multirow{2}{*}{ Isolated bacteria } & \multicolumn{2}{c}{ 16S rRNA } & & nifH \\
\cline { 2 - 3 } \cline { 5 - 6 } & \multicolumn{1}{c}{ Best hit spesices } & best hit OTU ID & & Best hit spesices & Accession number \\
\hline SB4-3 & Bradyrhizobium japonicum & denovo3518 & & Bradyrhizobium japonicum & LC510362 \\
L14 & Rhizobium sp. & denovo5515 & & Bradyrhizobium elkanii & LC510363 \\
10y-6 & Rhizobium sp. & denovo950 & & Uncultured bacterium & LC510368 \\
4y-1 & Rhizobium sp. & denovo950 & & Uncultured bacterium & LC510369 \\
KB1-2 & Rhizobium sp. & denovo950 & & Uncultured bacterium & LC510366 \\
GP1-3 & Rhizobium sp. & denovo950 & & Uncultured bacterium & LC510367 \\
L8 & Agrobacterium sp. & denovo12448 & & Uncultured bacterium & LC510364 \\
A4 & Agrobacterium sp. & denovo12448 & Uncultured bacterium & LC510365 \\
\hline
\end{tabular}

has isolated from sugarcane as plant growth promoting bacteria in not only Brazil but also in Okinawa, Japan, was not identified in Kagawa (Asis et al. 2000; Cavalcante and Dobereiner 1988; Lino et al. 2012). We could not find Acetobacter from both soils, soil-1 and soil-10, indicating root endophytic bacteria depends on the soil bacterial community. These characters of endophytic bacteria in Kagawa sugarcane might produce unique flavor for Wasanbon sugar.

To know the character of nitrogen-fixing bacteria, bacteria was isolated by two methods; one was used direct isolation by grinding the roots and spread it on HM plates, the sterilization process followed the previous method (Duangkhet et al. 2018). The second methods was trapping by using nodules. The sterilized root of sugarcane was grinded and directly inoculated to soybean, peas and common bean. Then bacteria was isolated from nodules. Through 16S rRNA sequence, the most of isolated bacteria using HM plates were identical to the registrations of denovo950, which belong to Rhizobium sp. and some bacteria were denovo5515, denovo 12448, which were classified as Rhizobium sp., or Agrobacterium sp.(Figure 2A, Table 2). We could only isolate Bradyrhizobium sp. from trapping soybean nodule (Table 2). After isolation of bacteria, nifH was amplified using previously reported nifH primers (Laguerre et al. 2001). Resulting accession number of isolates, SB4-3, L14, L8, A4, KB1-2, GP1-3, 10y-6, and 4y-1, are LC510362-LC510369, respectively (Table 2). The sequencing data showed that not only Rhizobium sp. or Bradyrhizobium sp. but also Agrobacterium sp. contain nifH genes. The phylogenetic tree of nifH revealed that the isolated bacteria belong to at least two (Figure 2B). The nifH gene of SB4-3 strain was derived from Bradyrhizobium sp. and another nifH gene of isolates which belong to Rhizobium sp. and Agrobacterium sp. by $16 \mathrm{~S}$ rRNA were derived from uncultured bacterium (Table 2). This phylogeny is not the strongest evidence for the horizontal-transfer of nifH gene. Verification of a horizontal-transfer event is difficult with this limited data. Nevertheless, our data of nifH phylogeny showed unexpected features that the gene transfer might exist. More data is needed to prove this hypothesis.
In conclusion, we identified the soil bacteria and endophyte bacteria in the roots of field-grown sugarcane in Kagawa. This report is the first on $S$. sinense, which is used to produce Wasanbon. Diversity was partially different from that in Brazilian and Japanese sugarcane, S. officinarum, which might produce unique flavor for Wasanbon sugar. Many Rhizobium sp. and Agrobacterium sp. with nifH were isolated. In the future, the relationship between the application of nitrogen-fixing bacteria and the production of Wasanbon should be studied.

\section{Acknowledgements}

This study was supported by the Special Coordination Funds for Promoting Science and Technology from the Ministry of Education, Culture, Sports, Science and Technology of Japan (25450084 to MN). We thank raw material production association of Wasanbon sugar for supplying the sugarcane and soil.

\section{References}

Asis CA Jr, Kubota M, Ohta H, Arima Y, Chebotar VK, Tsuchiya K, Akao S (2000) Isolation and partial characterization of endophytic diazotrophs associated with Japanese sugarcane cultivar. Soil Sci Plant Nutr 46: 759-765

Bissett A, Fitzgerald A, Meintjes T, Mele PM, Reith F, Dennis PG, Breed MF, Brown B, Brown MV, Brugger J, et al. (2016) Introducing BASE: The biomes of Australian soil environments soil microbial diversity database. Gigascience 5: 1

Boddey RM, Urquiaga S, Alves BJR, Reis V (2003) Endophytic nitrogen fixation in sugarcane: Present knowledge and future application. Plant and Soil 252: 139-149

Caporaso JG, Kuczynski J, Stombaugh J, Bittinger K, Bushman FD, Costello EK, Fierer N, Peña AG, Goodrich JK, Gordon JI, et al. (2010) QIIME allows analysis of high-throughput community sequencing data. Nat Methods 7: 335-336

Cavalcante VA, Dobereiner J (1988) A new acid-tolerant nitrogenfixing bacterium associated with sugarcane. Plant and Soil 108: 23-31

Dong M, Yang Z, Cheng G, Peng L, Xu Q, Xu J (2018) Diversity of the bacterial microbiome in the roots of four Saccharum species: S. spontaneum, S. robustum, S. barberi, and S. officinarum. Front Microbiol 9: 267

Duangkhet M, Chikoti Y, Thepsukhon A, Thapanapongworakul P, Chungopast S, Tajima S, Nomura M (2018) Isolation and characterization of rhizobia from nodules of Clitoria ternatea in Thailand. Plant Biotechnol 35: 123-129 
Govindarajan M, Kwon SW, Weon HY (2007) Isolation, molecular characterization and growth-promoting activities of endophytic sugarcane diazotroph Klebsiella sp. GR9. World J Microbiol Biotechnol 23: 997-1006

Klindworth A, Pruesse E, Schweer T, Peplies J, Quast C, Horn M, Glöckner F (2013) Evaluation of general 16S ribosomal RNA gene PCR primers for classical and next-generation sequencingbased diversity studies. Nucleic Acids Res 41: e1

Laguerre G, Nour SM, Macheret V, Sanjuan J, Drouin P, Amarger N (2001) Classification of rhizobia based on nodC and nifH gene analysis reveals a close phylogenetic relationship among Phaseolus vulgaris symbionts. Microbiology 147: 981-993

Lauber CL, Hamady M, Knight R, Fierer N (2009) Pyrosequencingbased assessment of soil $\mathrm{pH}$ as a predictor of soil bacterial community structure at the continental scale. Appl Environ Microbiol 75: 5111-5120

de Matos GF, Zilli JE, de Araújo JLS, Parma MM, Melo IS, Radl V, Baldani JI, Rouws LFM (2017) Bradyrhizobium sacchari sp. nov., a legume nodulating bacterium isolated from sugarcane roots. Arch Microbiol 199: 1251-1258

Matsuoka M (2006) Sugarcane cultivation and sugar industry in Japan. Sugar Tech 8: 3-9

Sajjad Mirza MS, Ahmad W, Latif F, Haurat J, Bally R, Normand P, Malik KA (2001) Isolation, partial characterization, and the effect of plant growth-promoting bacteria (PGPB) on micropropagated sugarcane in vitro. Plant and Soil 237: 47-54

Olivares FL, Baldani VLD, Reis VM, Baldani JI, Dobereiner
J (1996) Occurrence of the endophytic diazotrophs Herbaspirillum spp. in roots, stems, and leaves, predominantly of Gramineae. Biol Fertil Soils 21: 197-200

Paungfoo-Lonhienne C, Lonhienne TGA, Yeoh YK, Webb RI, Lakshmanan P, Chan CX, Lim P-E, Ragan MA, Schmidt S, Hugenholtz P (2014) A new species of Burkholderia isolated from sugarcane roots promotes plant growth. Microb Biotechnol 7: $142-154$

Lino T, Suzuki R, Kosako Y, Ohkuma M, Komagata K, Uchimura T (2012) Acetobacter okinawensis sp. nov., Acetobacter papayae sp. nov., and Acetobacter persicus sp. nov.: Novel acetic acid bacteria isolated from stems of sugarcane, fruits, and a flower in Japan. $J$ Gen Appl Microbiol 58: 235-243

Tejera N, Luch C, Martìnez-Toledo MV, Gonzàlez-López J (2005) Isolation and characterization of Azotobacter and Azospirillum strains from the sugarcane rhizosphere. Plant and Soil 270: 223-232

Urquiaga S, Xavier RP, de Morais RF, Batista RB, Schultz N, Leite JM, Maia e Sá JM, Barbosa KP, de Resende AS, Alves BJR, et al. (2012) Evidence from field nitrogen balance and $15 \mathrm{~N}$ natural abundance data for the contribution of biological N2 fixation to Brazilian sugarcane varieties. Plant and Soil 356: 5-21

Yeoh YK, Dennis PG, Paungfoo-Lonhienne C, Weber L, Brackin R, Ragan MA, Schmidt S, Hugenholtz P (2017) Evolutionary conservation of a core root microbiome across plant phyla along a tropical soil chronosequence. Nat Commun 8: 215 